\title{
Holistic Interdisciplinary Design - Everyone Does Everything (Engineering Students as Sculptors)
}

\section{Prof. Craig Baltimore, California Polytechnic State University, San Luis Obispo}

Dr. Baltimore is a Professor in Architectural Engineering at California Polytechnic State University, San Luis Obispo. He is also a licensed California Structural Engineer with extensive industry experience. Current research and engineering interest are in sustainable knowledge transfer to developing nations; concentrated solar power for urban areas; masonry design, technology, and sustainability; and active learning for higher education. His is actively involved with The Masonry Society, Research in Sustainable Grout for Masonry, Elected Official for Local Community Governance, and Teaching Full Time.

\section{Dr. Allen C. Estes, California Polytechnic State University, San Luis Obispo}

Allen C. Estes is a Professor and Head for the Architectural Engineering Department at California Polytechnic State University in San Luis Obispo. Until January 2007, Dr. Estes was the Director of the Civil Engineering Program at the United States Military Academy (USMA). He is a registered Professional Engineer in Virginia. Al Estes received a B.S. degree from USMA in1978, M.S. degrees in StructuralEngineering and in Construction Management from Stanford University in 1987 and a Ph.D. degree in Civil Engineering from the University of Colorado at Boulder in 1997. 


\section{Holistic Interdisciplinary Design: \\ Everyone Does Everything (Engineering Students as Sculptors)}

\section{Introduction}

The ability to offer students an interdisciplinary experience under a team work setting is invaluable in preparation for a career in the built environment. A hands-on approach coupled with a real project presents unique opportunities in student learning. Learning in regards to the dynamics of team personalities, deadlines, approval procedures, and deliverables. One such hands-on based real project was to design, build, and install an $800 \mathrm{lb}$., $20 \mathrm{ft}$. long, and $10 \mathrm{ft}$. tall sculpture. The sculpture was to be built of recycled steel of a mustang in 10 weeks for the University’s library Spring 2016 exhibit. The project gave the students direct exposure to the phases required to take a highly constrained construction project from conception to completion (Impacted Project Delivery). Under the constraints of limited time, limited budget, unique materials, university regulatory requirements, and confined site location (second floor of library), the students learned how impacted constraints affect the design, engineering, and construction process. This paper outlines the methods used by the faculty adviser to facilitate student success.

The collaboration among departments and across colleges is encouraged and facilitated by the university. This focus on interdisciplinary experiences and opportunities can be seen in past senior project collaborations. ${ }^{1,2,3,4,5,6,7,8}$ The group of students consisted of more than engineering students. The group was made up of students from the following majors.

- Architectural Engineering (10 students)

- Architecture (1 student)

- Art (2 students)

- Horticulture and Crop Science (3 students)

The project was a capstone class, thus the focus was for the students to draw upon their entire engineering education, as opposed to learning specific new skills or topics. The pedagogy was to use the experience itself to educate, as opposed to a classroom and text book. In using the experience for education a "road map" was needed to keep awareness of learning. This roadmap was to create a global statement to guide (stay out of the weeds), create a template for learning opportunities through accomplishment (establish expectations up front), and gain "buyin” from all team members. The term "buy-in” is from industry and it means that all parties agree to the expectations. In this case the buy-in was mostly in the form of homework assignments (intermediate deliverables). The mode of execution was to use the efficiencies of small teams to complete tasks. The momentum was facilitated through weekly meetings and accountability. Assessment was accomplished in peer form through presentations to the team or actual deliverable documents. The outcome was the on-time installation of the sculpture. A similar methodology has been tried in educational experiences in creating structures with K'nex toys. ${ }^{9,10}$ 


\section{High Impact Strategies}

High Impact Projects have a constraint or multiple constraints that are considered outside the norm of typical projects. For example, time constraints may be squeezed, site conditions may be unique, or the project itself may be non-typical. This capstone project had the high impact constraint of time (10 weeks) and unique site (second floor a public library). The strategy employed was one of guided autonomy, where there is an overseer (one or two people) to guide the project, while the actual tasks were accomplished with small groups who only had the responsibility to meet a deadline with a deliverable. The small group had the autonomy to accomplish the task using their experience and expertise - student's toolbox of skill sets.

The initial group meeting was to gain buy-in from everyone and to confirm the responsibilities and role of the overseer. The role of the overseer is to guide, which may include hard decisions to keep the project on track, and the responsibility is to enforce deadlines and produce deliverables. Once buy-in was gained, more conventional project planning and performance was employed. The project planning was divided into traditional intermediate goal phases conceptual (or schematic) design, design development, construction, and installation. The project performance incorporated small group tasks and accountability by weekly meetings and continuous contact (gmail group text and gmail documents). Below is an outline of pedagogy.

- The phases were defined by intermediate milestones (concept, development, construction, installation, and removal);

- Project progress relied on a division of responsibility - groups had autonomy with hard deadlines and deliverables (many leadership/responsibility roles were needed);

- Small team assignments required trust among teams - divide and conquer (it was recognized that everyone could not participate in every aspect);

- Parallel processing - many tasks progressing simultaneously (example: material collecting occurred during the concept and development phases);

- Mandatory weekly meetings held at 7:30 a.m. on Monday mornings

- Constant communication was essential (group messaging and shared gmail documents).

\section{The Project}

Given the incredibly short time period and unique site ( $2^{\text {nd }}$ floor of the Library), the students were skeptical about the project being a success - defined by delivering a sculpture in time for the exhibit opening. The students were assured that with proper project strategies, high impact projects like this can be successful. A strategy method that could be applied to life-long learning.

The significance of the project is that it summarizes the holistic education students receive. The project also highlights student learning through doing. A summary of the phases follows.

During the conceptual design phase the students travelled to artist studios. The face to face interaction had a greater impact than in-class lectures. The time impact of the project demanded this immersion style of learning. To learn about artistic expression, the students physically interacted with the art, and had face-to-face interaction with the artist inside the studio. The 
artist demonstrated a step by step process for making a study model. Similarly, the subject of the sculpture was a horse, so the students also visited the Cal Poly equine center as opposed to surfing the net for pictures. The students said they got a much better understanding of scale, smell, and texture through the visit. In Figure 1, artist David Sattino, describes “The Juice” of artistic inspiration. A demonstration on how to make a quick study model is given in Figure 2.

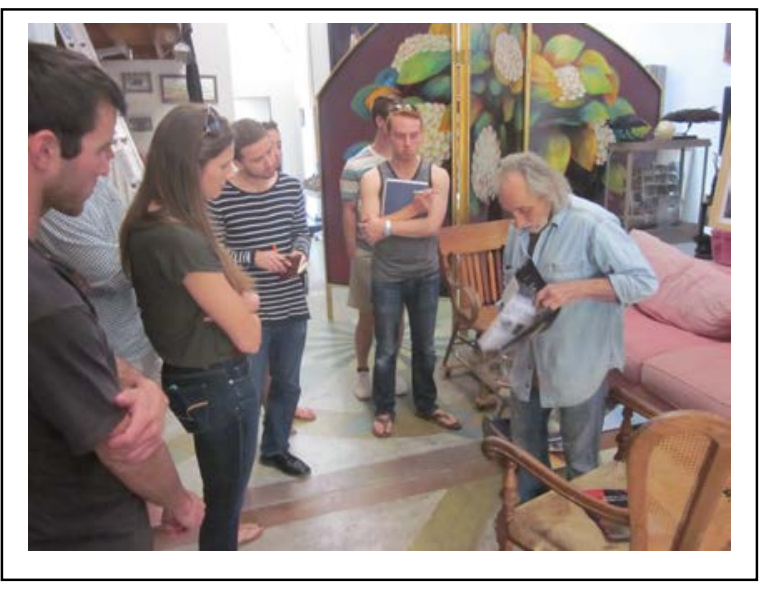

Figure 1: Artist David Sattino and "The Juice”

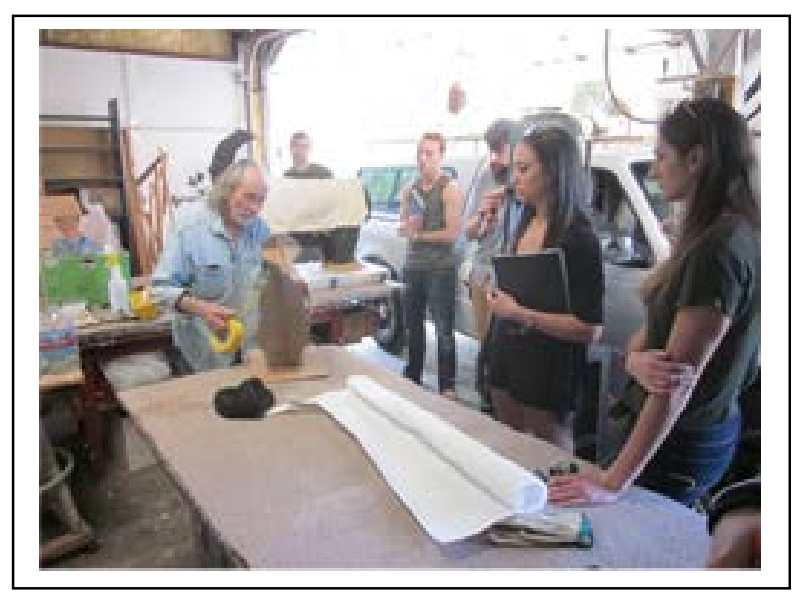

Figure 2: A quick study model demonstration

During the design development phase, classroom instruction was replaced by "discovery assignments” where students were given a topic and guidance. Discovery assignments is a terminology used uniquely by the adviser of the project. A discovery assignment is education through self-guided experience. The students then made presentations to the group. In this manner, multiple interpretations (as opposed to only having the instructors') are presented and discussed in a short period. For example, all students had to present the essence of horse. Figure 3 offers some student interpretations of the essence of a horse.

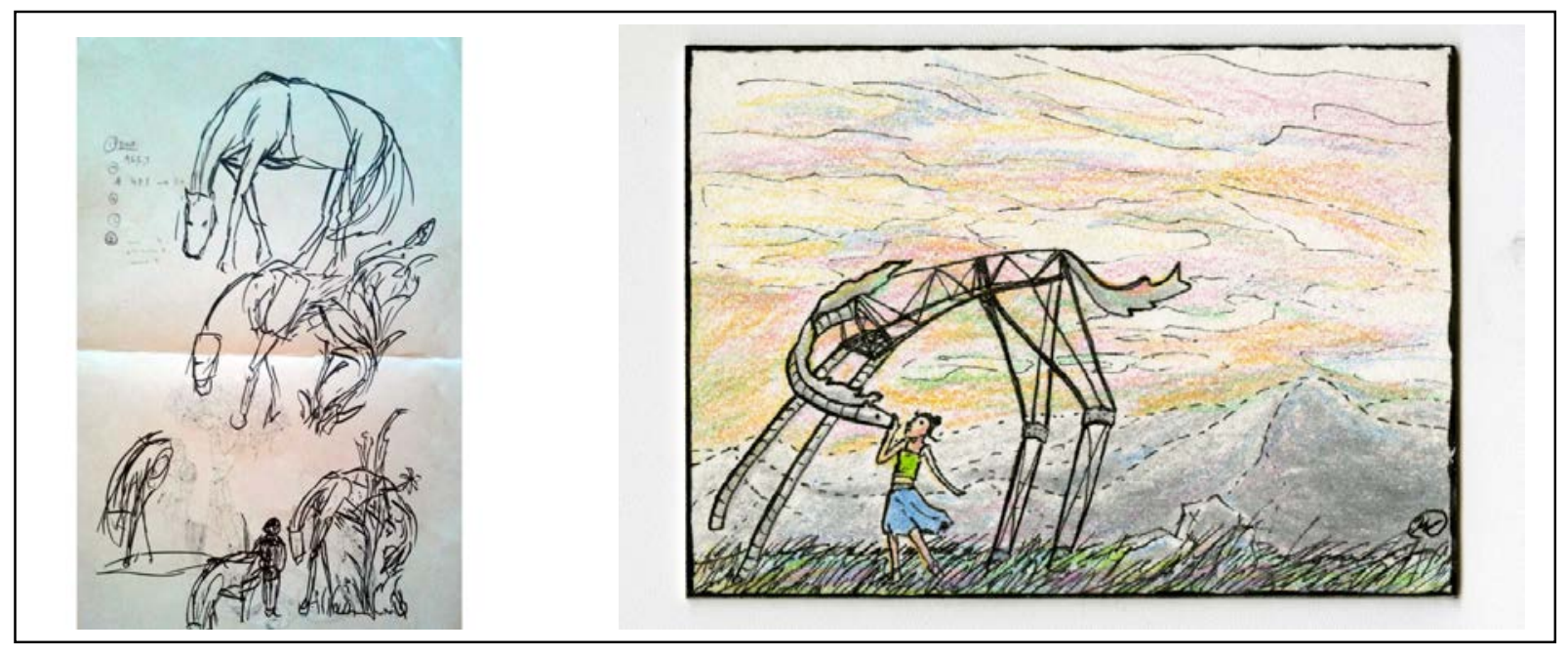

Figure 3: Student sketches of an essence of horse statue 
Then after the presentations, the students were combined into teams of two to make a study model of massing of the sculpture. No restrictions were given and students used 3D printing, chicken wire, clay, and many other media for the initial study (Figure 4). The variety was exceptional in learning about form.

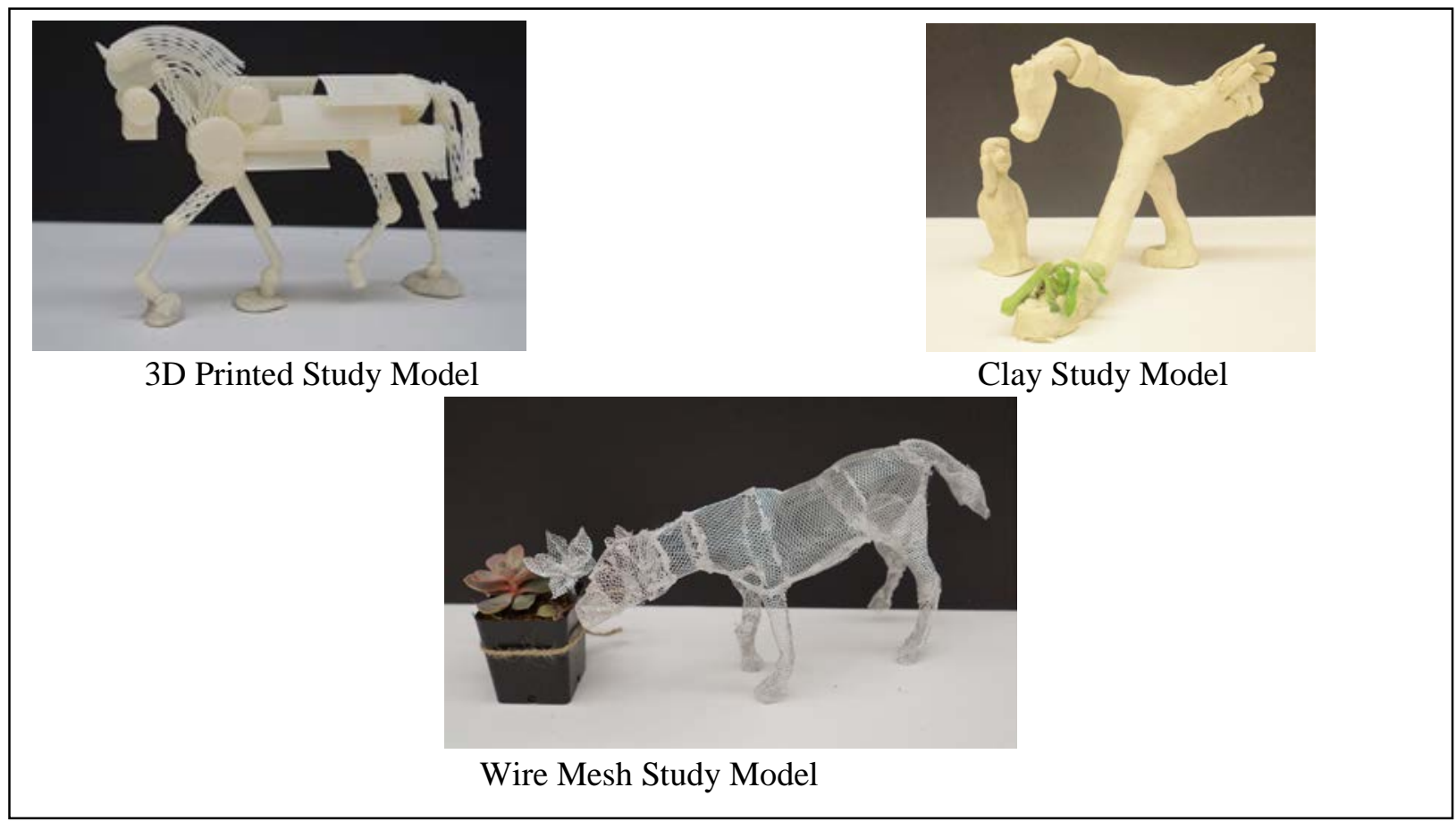

Figure 4: Student sketches refined into first concept study models

After a team meeting/discussion, the students formed two groups to develop a final concept model that will be used as a basis to engineer and to build the statue. The two versions were quite a contrast and highlight the personalities and disciplines of the group (see Figure 5 below).

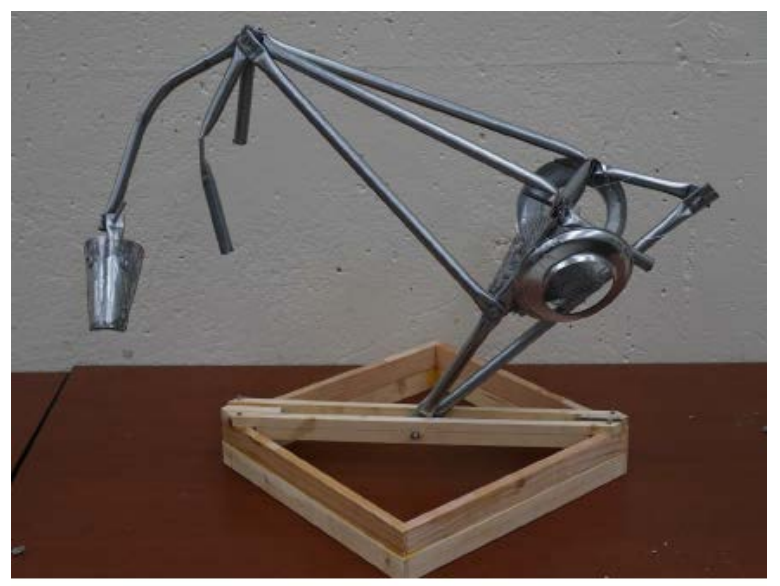

Abstract

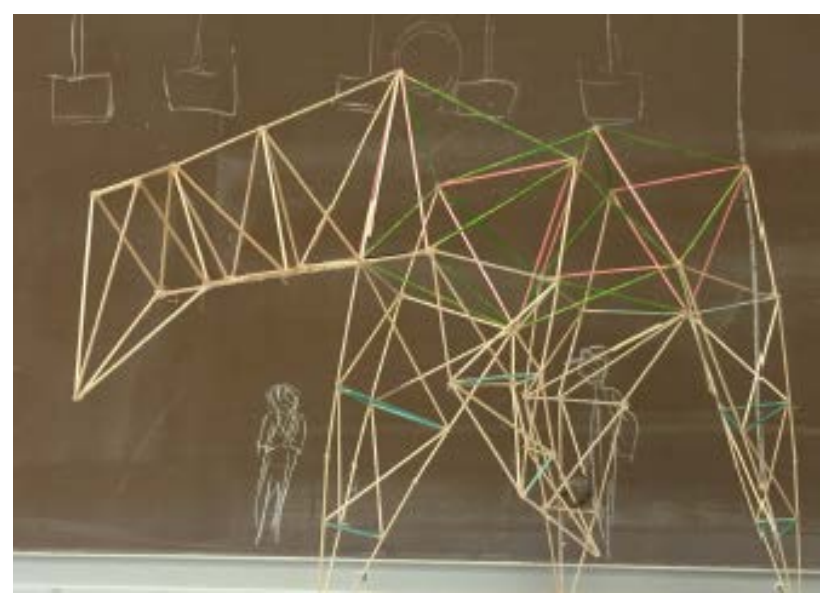

Truss

Figure 5: Final statue concept models 
When the students reviewed their accumulation of recycled material and which design would have the highest probability of success given the tight time schedule, the Truss concept statue was chosen.

In review, the creative experience started with the individual in order to gain a wide range of voice (16 students). And progressed into a group consensus agreement of the final design.

- Individual Input - The essence of horse. This step included visit to university horse unit.

- Two Member Team Design - Concept Study Models. The multiple ideas from the individuals is developed in a conceptual study model. This step included a visit to a professional artist studio.

- Two Group Team Designs - The final concept model. The time constraint of the project prevented a more gradual development of the conceptual study models. And the students divided themselves into two teams, where the member of the teams had the same "vision".

- Consensus Agreement of the Statue !!

The construction, installation, and removal phases were straightforward yet physical activities of Learn-by-Dong through cutting, welding, grinding, carrying, bolting, etc. The construction required a lot of welding and most structural engineering students get very little exposure to this skill. See Figure 6 below for on the job learning.

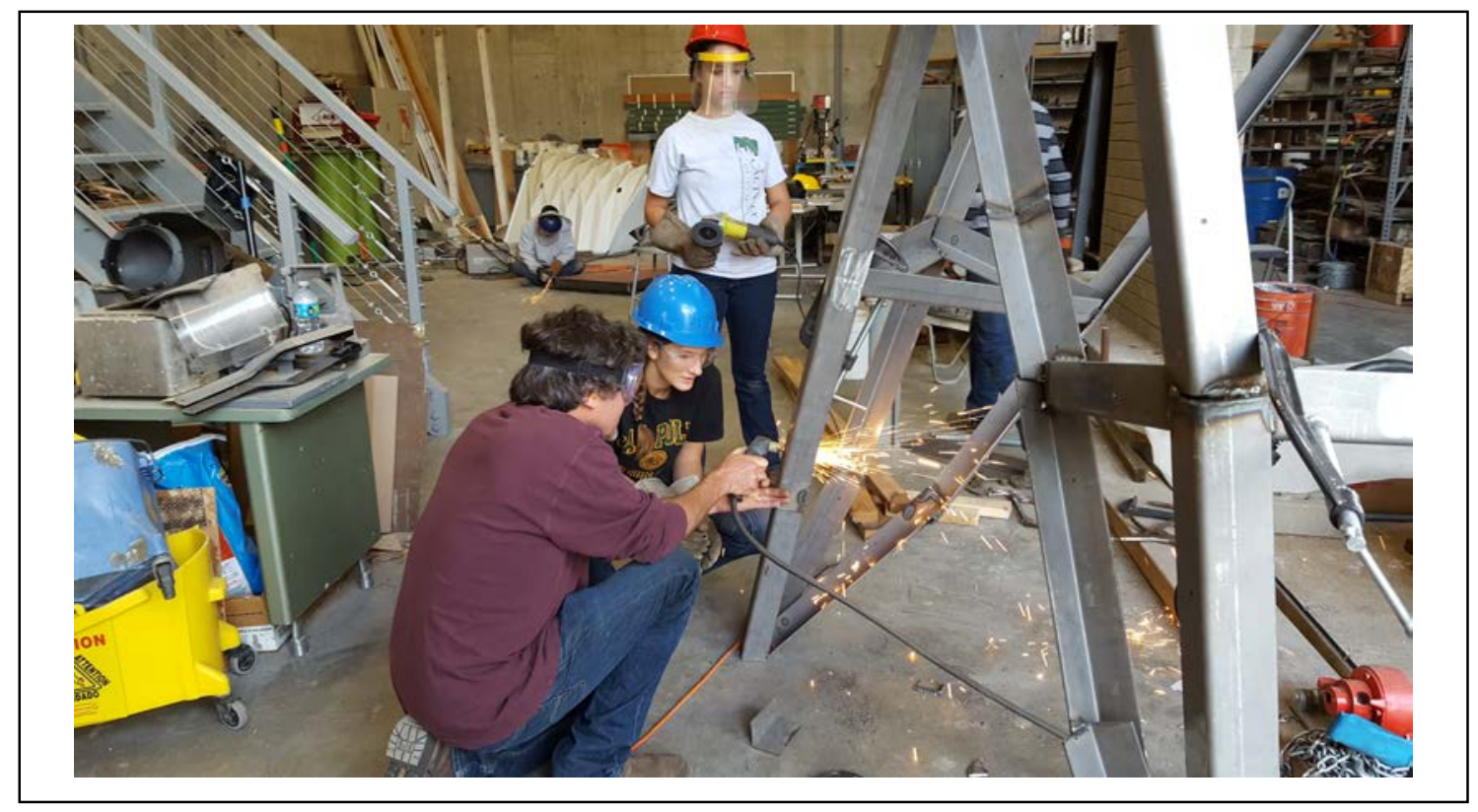

Figure 6: Learn-by- Doing metal construction skills.

They had to learn fast and a number of decisions were made regarding the order of construction and maintaining a stable structure. Also during this phase, the students were required to have face-to-face meeting with any approval or authorization persons. The short time line demanded these face-to-face meetings which helped build relationships and trust. The construction team takes a time for a group photo, shown in Figure 7 (next page). 


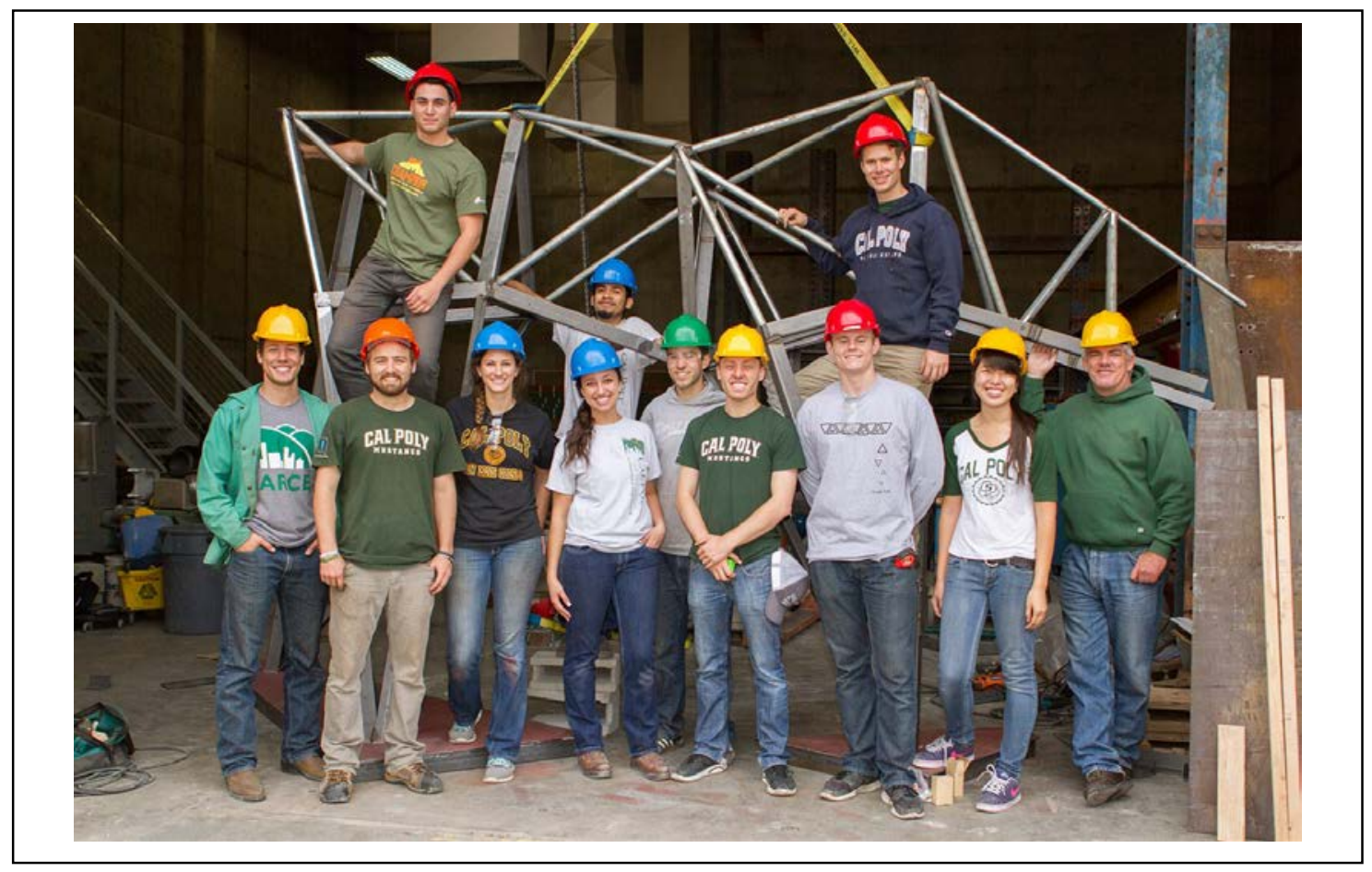

Figure 7: Off-Site construction and break time for a group photo.

It is noted that the site location of second floor of the library presented a design challenge. The freight elevator of the library was too small ( $5 \mathrm{ft}$ wide by $7 \mathrm{ft}$ high) for use. The solution was to divide the statue into the largest pieces that could be carried into place. The structure therefore needed to be designed and built in sub-sections that could be disassembled, transported and reassembled on site. Figure 8 shows sub-sections prepositioned for transport. Figure 9 shows the students move one sub-section to the second floor of the library.

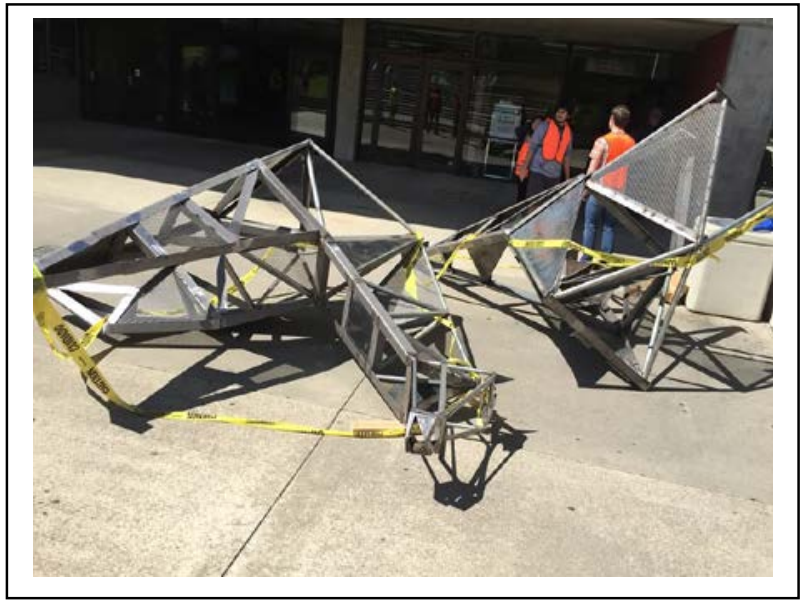

Figure 8: Staging the statue outside of the library

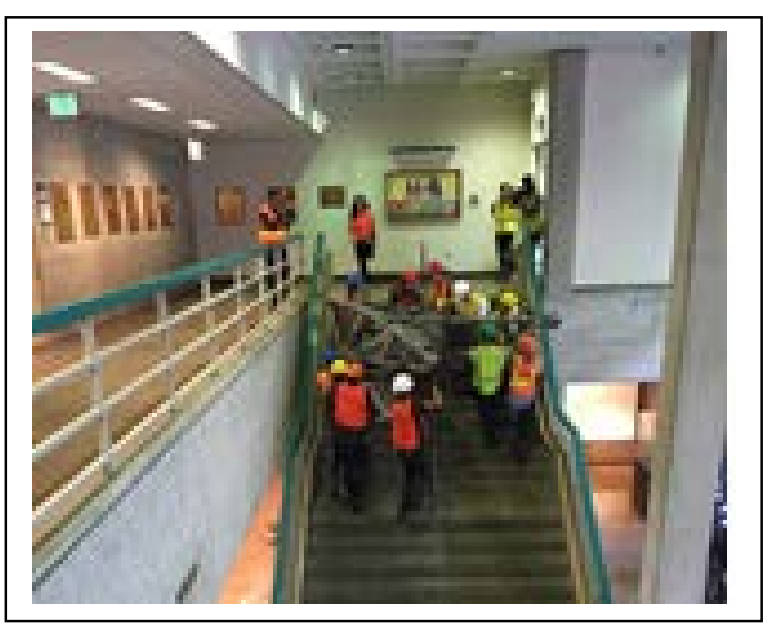

Figure 9: Hand carry installation 
The Cal Poly Mustang was on display for several weeks in the library and was featured at the annual Green and Gold banquet. ${ }^{12}$ Figure 10 shows the statue on display. It was removed by disassembly into subsections in the same manner that is was constructed. It remained in the high bay lab while a new group of students is arranging for the permitting and foundation design/construction that will allow it to be on permanent display on Cal Poly.

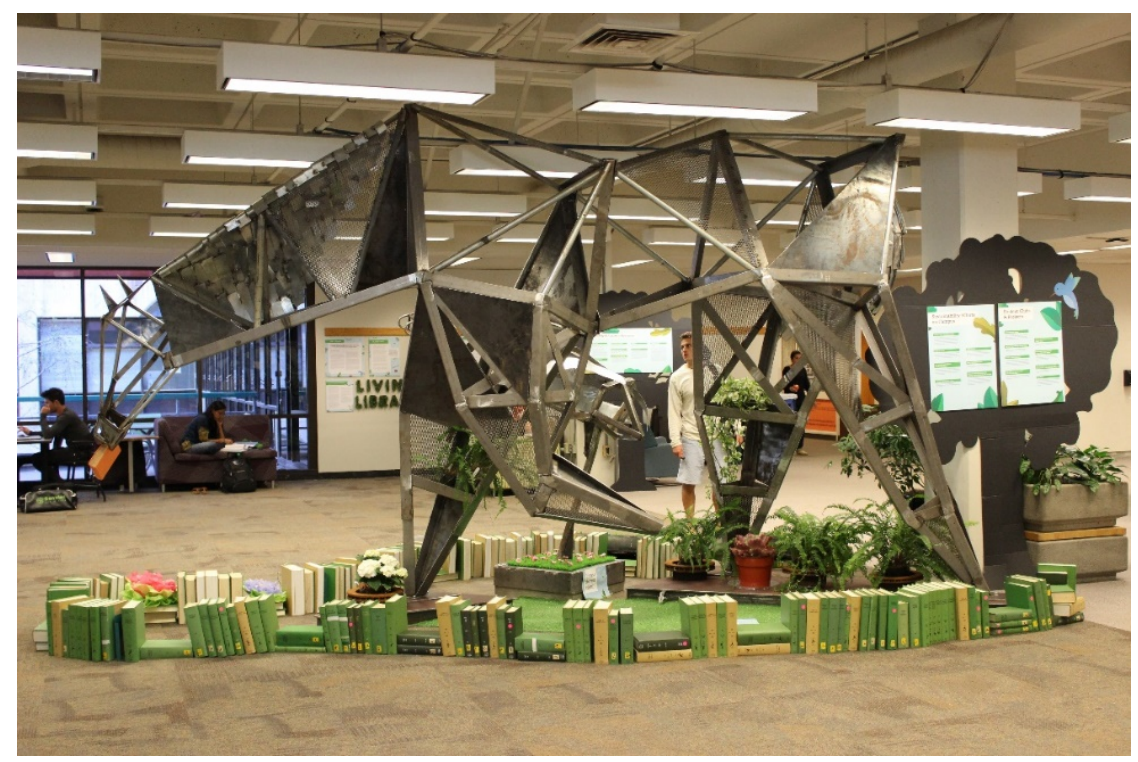

Figure 10: The statue on display on the second floor of the library

\section{Conclusion}

The major lesson learned from the project is the necessity of an overseer combined with autonomy of project groups for the success of high impacted project. High impacted projects do not have the luxury of a micro-manager or a draconian authority. The high constraint relies on the autonomy of project groups to use their expertise and experience to supply the agreed deliverable on time. However, a project group does not have the freedom to reinvent or deviate from the agreed project directions and goal, and this is responsibility of the overseer to guide; and if needed - correct. This concept is a simple statement, but it is far more complex. The overseer has to be fully experienced in all aspects of the project, such that continual assessment and/or guidance can be given. There must be breadth of vision to allow the project groups to implement their own solutions, and have the self-confidence and self-esteem to allow project groups to succeed. This requires a willingness to leave the ego at the table and relish the success of others. In this project, for example, the student groups were making great progress through the concept phase and presented their final model for construction. To this point, the students experienced autonomy in applying their skillsets in combination with newly learned material and were making deadlines and producing agreed deliverables. However, the final solution deviated too far from the University requirements and the overseers paused the project and challenged the students to refine it to meet the University requirements. Autonomy is the autonomy to produce an agreed upon deliverable, not the autonomy to deviate from what was agreed.

The author has had great success in implementing method of guided autonomy and encourages others to try and experiment with it. 


\section{Assessment}

Assessment occurred in the form of the actual deliverable - the statue - and with exit comments. Below are some of the comments.

As an architectural engineering student, I have worked with architecture student and construction management students in my major. But in this project we worked with graphic art students, horticulture club, the administration at the library, and professional artists. I learned some much more on how other disciplines view and solve problems. - Arch. Eng. student

The project showed me the little stuff that occurs in a project that my classes did not even touch on. Arch. Eng. student

It was super cool and interesting to see how the engineering students approach design, because it is "way" different than how an architecture approaches design. - Arch. student

It is helpful to see the different approaches of execution, and I would "totally" work with everyone again. - Graphic Art student

The comments from the advisers was sometimes very truthful and "kind-of" hard to hear at first, but looking back, it was super helpful. - Arch Eng. student

The biggest challenge was using recycled material, because first you had to gather the materials. Then you had make the design fit the materials and the materials fit the design - a give and take process. Arch. Eng. student

I really liked the big groups because the creativity was always different. As an engineer you sometimes get stuck in a mindset. And then someone different comes in with a different mindset, like the professional artist Ivan - whoa, different. - Arch Eng. student

It was interesting to step back and stay on the sidelines and watch and not solve the issues for the students. I was thinking, "The students shouldn't be doing that or they should be doing this. But I stayed quiet and the students were able to work through everything really well.” - professional artist Ivan Mclean

At the beginning things were kind of slow, but that might have been the engineer's artistic creativity. But at the end, it really came together. We worked well under pressure. You don't have time to linger on decision making. You have to make a decision and go with it. It turned out great. - Art and Design student

Working with other disciplines doesn't happen to often in my major. It was like working with a client and a real world experience. - Graphic Art student

It took away the experience of learning to ask the right questions to get the information I need to my part. - Graphic Art student

I am proud of what we did. Check it out. https://vimeo.com/170082623 


\section{Bibliography}

${ }^{1}$ Clay, G., M. McDonald, J. Mwangi, G. Starzyk, \& J. Nelson. Collaborative Teaching and Learning: Applying an Integrated Project delivery (IPD) Model in Design Education. Urban/Nature: CELA 2011/Proceedings of the Council of Educators in Landscape Architecture. Los Angeles, CA, 2011.

${ }^{2}$ Estes, A.C., Nuttall, B., Nelson, J., McDonald, M., and Starzyk "Interdisciplinary Design - Forming and Evaluating Team” 2013 ASEE Annual Conference and Exposition Proceedings, ASEE, Atlanta, 2013.

${ }^{3}$ Guthrie, J. Nelson, J., Nuttall, B. and Estes, A.C., "Interdisciplinary Capstone Design: Architects, Structural Engineers, and Construction Managers” Paper 2012-3497. 2012 ASEE Annual Conference and Exposition Proceedings, ASEE, San Antonio, 2012.

${ }^{4}$ Nuttall, B., Nelson, J., and Estes, A.C. “Interdisciplinary Design: The Saga Continues” Session M603. 2011 ASEE Annual Conference and Exposition Proceedings, ASEE, Vancouver, 2011.

${ }^{5}$ Nelson, J., Nuttall, B. and Estes, A.C. "Interdisciplinary Design: The Good, the Bad, and the Ugly" Paper 20101004. 2010 ASEE Annual Conference and Exposition Proceedings, ASEE, Louisville, 2010.

${ }^{6}$ Starzyk, G.F. and M. McDonald. The Collaborative Dance: Only Three Steps. Proceedings of the BIM Forum at Ecobuild America 2010. Washington, D.C., 2010.

${ }^{7}$ Starzyk, G.F., McDonald, M., Nuttall, B., Mwangi, J., \& Clay, G. Instructional Design for an Integrated Project Delivery Studio. Proceedings of the 46th ASC International Conference. Omaha, Nebraska, 2011.

${ }^{8}$ Vanasupa, L., K.E. McCormick, C.J. Stefanco, C. J., R.J. Herter, \& M. McDonald. Challenges in Transdisciplinary, Integrated Projects: Reflections on the Case of Faculty Members' Failure to Collaborate. Journal of Innovative Higher Education. 37/3, 2011.

${ }^{9}$ Estes, A.C. and Baltimore, C. “Using K'nex to Teach Large Scale Structures to Architects and Construction Students.” Paper 2014-9826. 2014 ASEE Annual Conference and Exposition Proceedings, ASEE, Indianapolis, 2014.

${ }^{10}$ ARCE Magazine, “K’nex Connection: Students Play with Toys, Learn About Structures.” Department of Architectural Engineering, California Polytechnic State University, p. 3, Summer 2014. http://content-calpolyedu.s3.amazonaws.com/arce/1/images/ARCE\%20News\%20Summer\%202014\%20Final.pdf accessed 5 March 2017

${ }^{11}$ ARCE Magazine, "Making a Mustang: An Interdisciplinary Team Designs and Builds a Massive Horse Sculpture” Department of Architectural Engineering, California Polytechnic State University, pp. 6-7, Summer 2016 http://content-calpoly-edu.s3.amazonaws.com/arce/1/images/ARCE\%20News\%202016\%20Final.pdf accessed 5 March 2017.

${ }^{12}$ Cal Poly, San Luis Obispo, “An Evening of Green and Gold”, last viewed June 2016. 